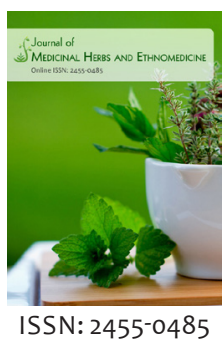

Received: April 08, 2021 Accepted: May 19, 2021 Published: July 03, 2021

*Corresponding author: Christian Bailly Email: christian.bailly@ oncowitan.com

\section{Walsura robusta Roxb. (Meliaceae), a little-known tree with a rich limonoid profile}

\author{
Christian Bailly* \\ OncoWitan, Lille (Wasquehal), 59290, France
}

\begin{abstract}
The plant Walsura robusta Roxb. (Meliaceae) is a robust tree largely distributed in south-east Asia, including provinces of southern China. A few traditional usages of the plant have been mentioned, notably for the treatment of microbial infections. But experimental studies using different types of plant extracts only revealed modest antibacterial effects, and no major antiparasitic activity. Walsura robusta Roxb. is a rich source of secondary metabolites. Several series of limonoids have been isolated from the leaves or the fruits of the plant, such as walsuronoid A-I, walsurins A-E, walsunoids A-I, walrobsins A-R and other cedrelone- or dihydrocedrelone-type limonoids, in addition to a few other terpenoids. All information about Walsura robusta Roxb. have been collated in this brief review. The analysis underlines the presence of two limonoids endowed with significant anticancer activities, walsuronoid B and cedrelone. They both activate the production of reactive oxygen species in cancer cells, modulate mitochondrial activities and induce apoptosis of cancer cells. Their molecular targets and mechanism of action are discussed. Walsura robusta Roxb. has a potential for the development of anticancer natural products. The use of the plant extracts could be further considered for the treatment of diseases with a cell proliferation component.
\end{abstract}

KEY WORDS: Anticancer agents, limonoids, Meliaceae, natural products, Walsura robusta.

\section{WALSURA ROBUSTA ROXB.: A ROBUST TREE}

The plant genus Walsura comprises about 50 different names but there are only 4 accepted specie names: W. pinnata Hassk., W. trichostemon Miq., W. villosa Wall. ex Hiern. and W. robusta Roxb (http://www.theplantlist.org). There are other commonly used names, such as W. cochinchinensis (Baill.) Harms and W. yunnanensis C.Y. Wu but they are both synonyms for Walsura pinnata Hassk. These plants, belonging to the Meliaceae family, are usually found in subtropical regions of Southern China, India, Indonesia, and the Asean member countries.

The specie Walsura robusta Roxb. (synonym: Surwala robusta (Roxb.) M. Roem.) is an evergreen large tree which can usually grow 20-30 meters tall, with large leaves (Fig. 1). The outer bark is grey-brown whereas the inner bark is pink-red, with a specific wood anatomy. The wood of W. robusta presents a much larger vessel pore density (308/sq.mm) than the wood of W. trifoliolata, W. tubulata, and W. chrysogyne (at 81-154/sq.mm). The fruits of W. robusta Roxb. are non-edible, in contrast to those of $W$. pinnata Hassk. which are sweet-tasting brown-orange fleshy berries. From a taxonomic point of view, W. robusta belongs to a distinct subgroup compared to other Walsura species (Clark,
1994). The tree can be found found in south-east Asia, notably in Vietnam (where it is called lòng tong), Cambodia, Thailand, Laos, Myanmar, and Malaysia. There is an old mention that the tree is commonly grown in Chittagong (Ghosh, 1968) and in the Rajkandi reserve forest of Moulvibazar, (Bangladesh) (Haque et al., 2018). There may be confusion about the name of the plant because several studies mention that the vernacular Bengla name for W. robusta in is bonlichu (or bonlichi), whereas other studies refer to bonlichu as a totally different tree, Xerospermum laevigatum Radlk. (Pasha and Uddi, 2019; Abdullah et al., 2020). W. robusta Roxb. is found also in the south of China, notably in the Yunnan, Guangxi, Guangdong, and Hainan provinces (Sakkatat, 2007).

\section{EXTRACTS OF WALSURA ROBUSTA ROXB. AND THEIR USES}

There are a few reports mentioning the traditional use of extracts of W. robusta Roxb. to treat various diseases and conditions. In Thailand, extracts of the leaves and twigs of the plant (called bonlichu) are used to treat microbial infections and diarrhea. In China, it may be named name "gesheshu" as mentioned in a study (Hou et al., 2013), although it is possible that this Chinese

Copyright: $\odot$ The authors. This article is open access and licensed under the terms of the Creative Commons Attribution License (http://creativecommons.org/licenses/by/4.0/) which permits unrestricted, use, distribution and reproduction in any medium, or format for any purpose, even commercially provided the work is properly cited. Attribution - You must give appropriate credit, provide a link to the license, and indicate if changes were made. 

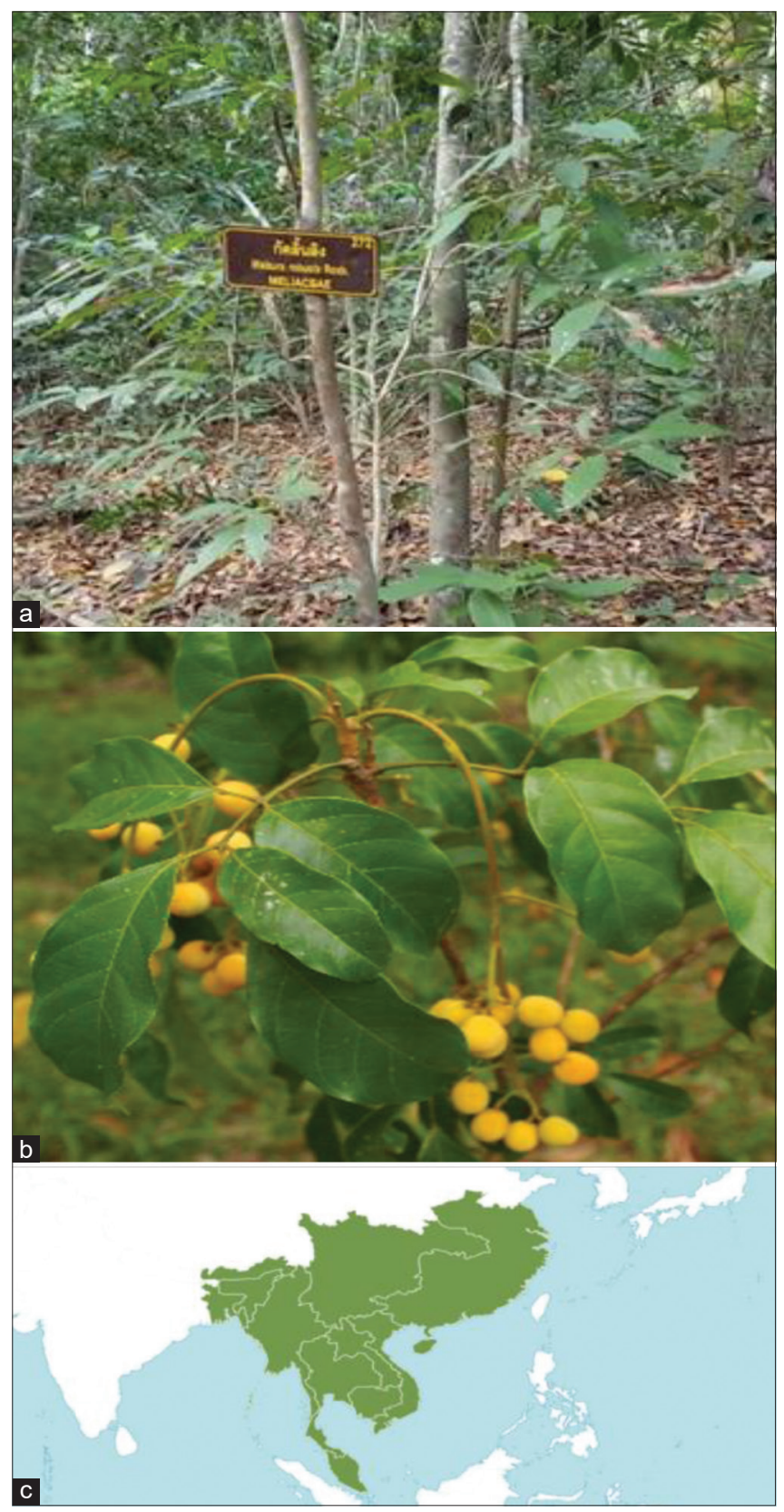

Figure 1: The plant Walsura robusta Roxb. (Meliaceae) and its geographic breakdown. (a) the tree. (b) leaves and fruits (http:// tracuuduoclieu.vn/walsura-robusta-roxb.html). (c) The plant can be found in Vietnam, Laos, Cambodia, Thailand, Myanmar, Malaysia, Bhutan, Bangladesh, and in provinces of south China (Yunnan, Guangxi, Guangdong, and Hainan) (http://www.plantsoftheworldonline. org/taxon/urn: Isid:ipni.org: names:579946-1)

name refers in fact to W. yunnanensis, as cited in another study (Luo et al., 2006). W. robusta seem to be used in traditional medicine in diverse countries in Asia, but there is a lack of robust information about this traditional usage. Moreover, there is also little experimental evidence to support the traditional medicinal use of W. robusta. Initially, a modest antibacterial activity was reported with an ethanolic plant extract found to inhibit the growth of a clinical isolate of methicillin-resistant Staphylococcus aureus (MRSA) and the S. aureus ATCC strain
25923 with a minimum inhibitory concentration (MIC) of $1.6 \mathrm{mg} / \mathrm{ml}$ (Voravuthikunchai and Kitpip, 2005a, 2005b). A better level of activity was observed using wood extracts of the plant against the enterohaemorrhagic Escherichia coli strain O157:H7, with MIC of 0.09 and $0.19 \mathrm{mg} / \mathrm{ml}$ for the aqueous and ethanolic extracts, respectively (Voravuthikunchai et al., 2004) but a later study reported a marginal bacteriostatic and bactericidal activities with a similar extract (Voravuthikunchai and Limsuwan, 2006). In another study, an aqueous extract of W. robusta was found to mildly inhibit the growth of Grampositive and some Gram-negative bacteria, including E. coli. In the same study, the plant extract was tested against trophozoites of the intestinal parasite Giardia intestinalis but no anti-giardial activity was observed (Voravuthikunchai et al., 2010). Clearly, there is not enough experimental data to support the traditional use of the plant as an anti-infectious agent.

\section{PHYTOCHEMICAL ANALYSES OF WALSURA ROBUSTA ROXB.}

Diverse types of secondary metabolites have been isolated from W. robusta, in particular limonoids which are heavily oxygenated, modified triterpenes frequently encountered in Meliaceae and Rutaceae (Citrus species) and to a lesser extent in Cneoraceae and Simaroubaceae (Tan and Luo, 2011; Tundis et al., 2014; Zhang and $\mathrm{Xu}, 2017)$. The major limonoids in $W$. robusta are named walsuronoids A-C, initially isolated from the leaves of the plant (Yin et al., 2007). Walsuronoid A (Fig. 2) bears a seco limonoid skeleton with a 3,4-peroxide bridge and walsuronoids $\mathrm{B}$ and $\mathrm{C}$ possess an $18(13 \rightarrow 14)$-abeo-limonoid skeleton. Walsuronoid $\mathrm{C}$ has been considered as an oxidation product of walsuronoid $\mathrm{B}$ because its furyl ring is easily oxidized when exposed to air in chloroform. A modest growth inhibition of the malaria parasite Plasmodium falciparum was observed with walsuronoids A and B (40\% inhibition at the dose of $40 \mu \mathrm{M})$ (Yin et al., 2007). Walsuronoid B was also identified from the fruits of the plant together with a series of linonoids, known as walsuronoid F-I and walsurins A-E (Fig. 2) and many other terpenoids (Zhang et al., 2017).

Walsuronoid B deserves a special mention because it has been shown to exert potent anticancer effects in vitro and in vivo (Geng et al., 2017). The compound dose-dependently inhibited the proliferation of several types of cancer cells, with $\mathrm{IC}_{50}$ in the range of 3-4 $\mu \mathrm{M}$. Walsuronoid $\mathrm{B}$ blocked cell cycle progression of HepG2 and Bel-7402 liver cancer cells ( $\mathrm{G}_{2} / \mathrm{M}$ arrest), with a concomitant up-regulation of cyclin $\mathrm{Bl}$ and down-regulation of (phospho)-cdc55C. The compound was found to trigger a massive apoptosis of these malignant cells, with activation of caspases and a drug-induced dysfunction of mitochondria and lysosomes (Fig. 3a). The molecular target of the drug is not known at present, but the compound enhanced the production of reactive oxygen species (ROS) and elevated the expression of the tumor-suppressor protein p53. Interestingly, walsuronoid $\mathrm{B}$ (at the intraperitoneal dose of $4 \mathrm{mg} / \mathrm{kg}$ ) displayed a marked anticancer activity in mice with xenografted HepG2 liver tumors, with an efficacy comparable to that of the standard drug cisplatin (Geng et al., 2017). The activation of the ROS/ 


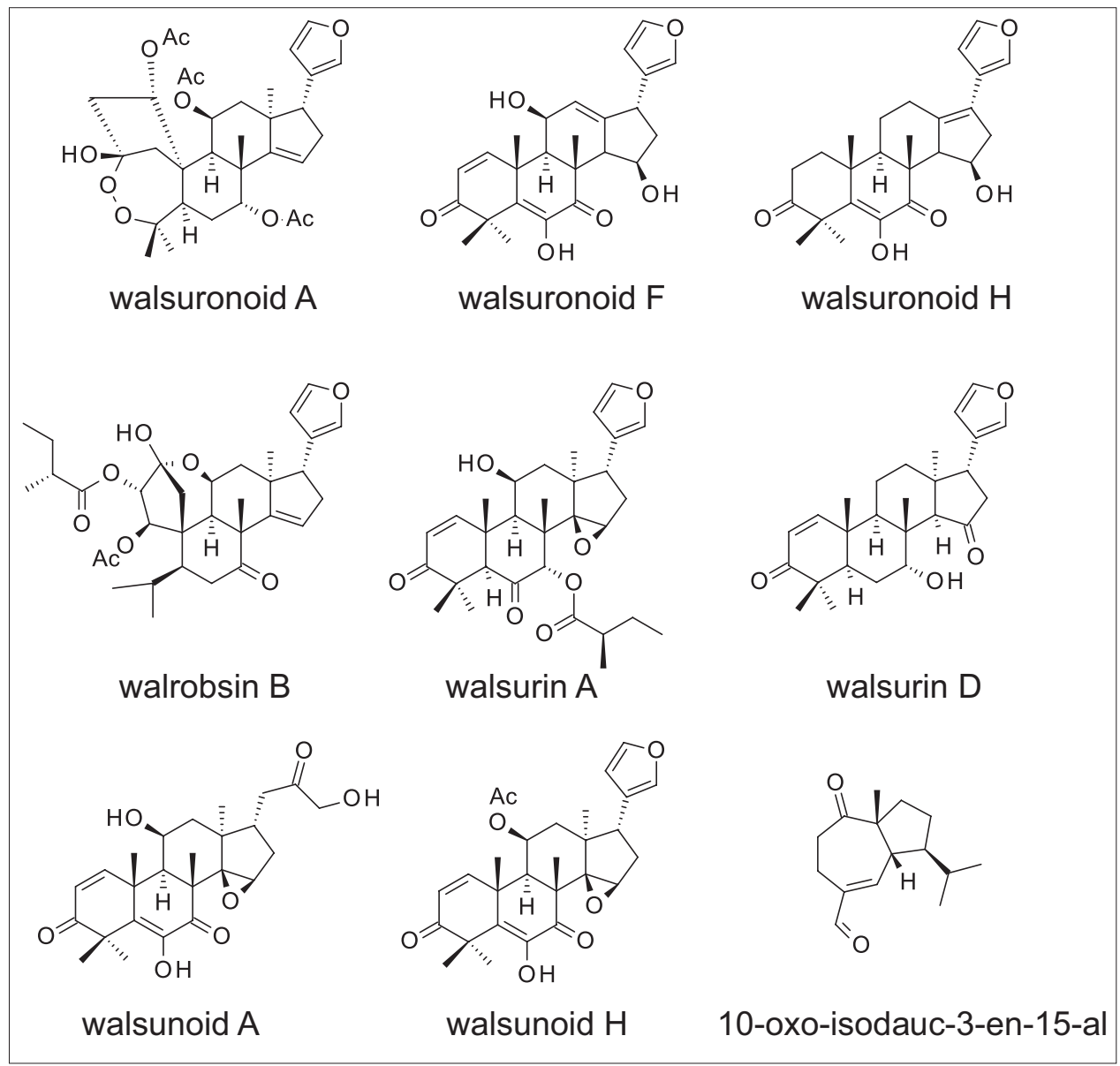

Figure 2: Chemical structures of selected natural products isolated from Walsura robusta Roxb

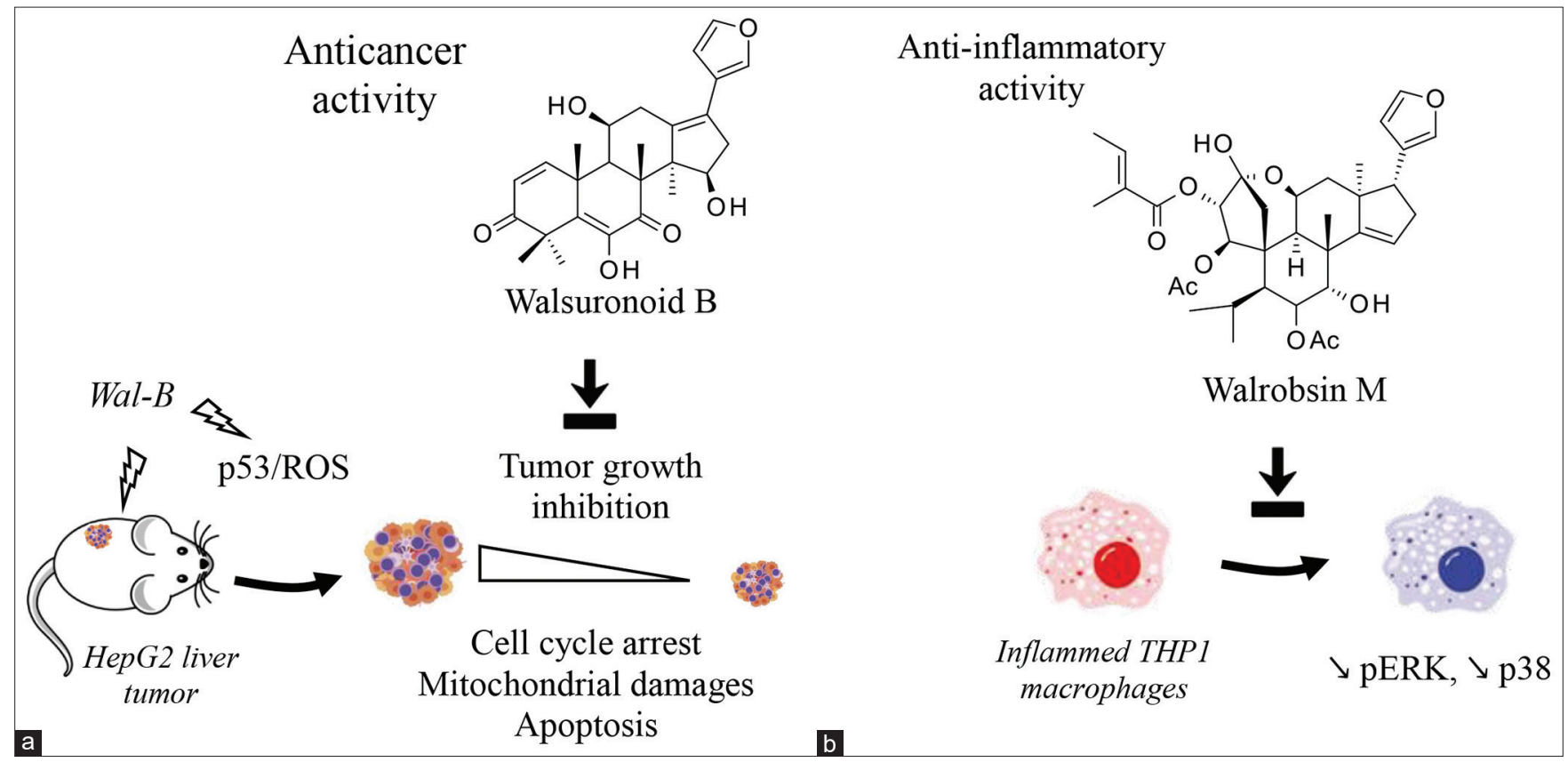

Figure 3: Schematic representation of (a) the anticancer activity of walsuronoid B and (b) the anti-inflammatory action of walrobsin M. Walsuronoid $B$ activates the production of reactive oxygen species (ROS) and the tumor suppressor protein p53, leading to apoptotic cell death (Geng et al., 2017). Walrobsin M represses the expression of the phosphorylated signaling proteins ERK (extracellular signal-regulated kinase) and p38 in THP1-like macrophages (stimulated with the skin pathogen Propionibacterium acnes), thereby inhibiting the MAPK signaling pathway (An et al., 2019) 
$\mathrm{p} 53$ signaling pathway is central to the mechanism of action of walsuronoid $\mathrm{B}$, as it is the case for other anticancer plant natural products like the cardiac glycoside odoroside A from the plant Nerium oleander Linn. (Chen et al., 2019), betulinic acid (Shen et al., 2017) and gambogic acid (Liang and Zhang, 2016) for examples. There is no doubt that walsuronoid $\mathrm{B}$ warrants further studies to better define its mode of anticancer action, tumor selectivity and molecular targets.

Another small group of limonoids isolated from W. robusta has been named walsunoids A-I, isolated together with different cedrelone-type limonoids such as $11 \beta$-hydroxyisowalsuranolide and 11 $\beta$-hydroxydihydrocedrelone (Wang et al., 2016). These compounds were tested against the human $11 \beta$-hydroxysteroid dehydrogenase type 1 (11 $\beta$-HSDl), the enzyme which reduces inert cortisone into active cortisol, and which is frequently implicated in metabolic diseases (obesity, diabetes). A modest inhibition of human $11 \beta$-HSDl was observed with walsunoid $\mathrm{H}$ (Fig. 2) in vitro $\left(\mathrm{IC}_{50}=9.9 \mu \mathrm{M}\right)$ (Wang et al., 2016).

Two other analogues with an atypical 5-oxatricyclo[5.4.1 $\left.{ }^{1,4}\right]$ hendecane ring system have been isolated from the root bark of the plant. They were named walrobsins A and B (Fig. 2). These two compounds showed no cytotoxic activity, but a modest anti-inflammatory activity was reported with walrobsin A. The compound was found to inhibit the release of the proinflammatory cytokine interleukin- $1 \beta$ from lipopolysaccharideactivated RAW264.7 macrophages and to dose-dependently inhibit the expression of the inducible nitric oxide synthase (iNOS) enzyme, the enzyme responsible for nitric oxide (NO) production (An et al., 2017). A subsequent phytochemical analysis from the root bark of $W$. robusta led to the identification of other compounds with a 5-oxatricyclohendecane ring system and named walrobsins C-to-R (An et al., 2019). The bioactivity of these compounds has not been deeply investigated but a preliminary evaluation indicated that walrobsin M (Fig. 3b) presents an interesting anti-inflammatory profile, with a druginduced down-regulation of the expression of protein phosphoERK and phospho-p38 in inflamed THP-1 macrophage cells (An et al., 2019).

The fruits of the plant also contain a series of compounds structurally similar to cedrelone (Fig. 2) and dihydrocedrelone, which were found to potentiate the cytotoxicity of the anticancer drug doxorubicin in human MCF-7/DOX breast cancer cells, normally resistant to the drug. These compounds could efficiently reverse the multidrug resistance (MDR) phenotype in vitro (Zhang et al., 2017). Cedrelone limonoids have been isolated from W. robusta, W. yunnanensis (Ji et al., 2014), Toona sinensis (Jiang et al., 2020) and from the leaves of Trichilia americana, another plant of the Meliaceae family (Ji et al., 2015). Acetylation of the cedrelone core affords cedrelone acetate, a synthetic molecule presenting enhanced cytotoxic properties and efficient to revert the malignant phenotype of cancer cells (Becceneri et al., 2020). Cedrelone itself is an interesting anticancer agent because this compound was found to activate the expression of the protein PBLD (phenazine biosynthesis-like domain-containing protein) which is often down-regulated in hepatocellular carcinoma (HCC) (Wu et al., 2019). PBLD functions as a tumor suppressor. An increase of the expression of PBLD could reduce HCC cell growth and invasion via inactivation of several tumorigenesisrelated signaling pathways (Li et al., 2016). Through the activation of PBLD in cells, cedrelone regulates the Ras and Ras-proximate-1 (Rapl) signaling pathways and this signaling action triggers apoptosis of cancer cell, while reducing cell proliferation and the epithelialmesenchymal transition (Wu et al., 2019). The antitumor capacity of cedrelone has been characterized in different experimental models, notably using drug-resistant human glioma cells (Cao et al., 2019) and leukemia cells (Wang et al., 2019). In both cases, the compound selectively affected the ERK/MAPK signaling pathway. A direct interaction of cedrelone with the ERKl kinase has been postulated, based on a computational docking analysis. The compound was predicted to bind to a small pocket on the protein, leading to the kinase activation (Fig. 4). Similarly, a combination of docking and molecular dynamic simulations has suggested that cedrelone could bind to the multi domain ceramide transfer protein (CERT), a protein implicated in sphingolipid metabolism and which allows the transport of ceramide from the endoplasmic reticulum to the Golgi apparatus (Fig. 4). Cedrelone would bind to the linked PH and START domains of CERT, thereby inhibiting the protein (Ghoula et al., 2020). Inhibition of CERT is considered as an appropriate mechanism to re-sensitize cancer cells to chemotherapy (Palau et al., 2018; Kumagai and Hanada, 2019). The anticancer effects of cedrolone have been evidenced using other cell types, including MDA-MB-231 breast cancer cells, NCI-H460 non-small cell lung cancer cells and A375 melanoma cells (Cazal et al., 2010; Fuzer et al., 2013). Cedrolone is an interesting natural product which also displays anti-fungal and insecticidal activities (Govindachari et al., 1995, 2000). It exhibits a sub-micromolar activity against the protozoan parasite Cryptosporidium parvum in vitro $\left(\mathrm{EC}_{50}=0.27 \mu \mathrm{M}\right)$ (Jin et al., 2019) and causes lethal and sublethal effects on the armyworm Spodoptera frugiperda (Giongo et al., 2016).

Other terpenes and sesquiterpenes have been isolated from W. robusta, such as the carotane sesquiterpene 10-oxo-isodauc3-en-15-al (Fig. 2) and its nitro derivative, both isolated from a methanolic extract of the plant leaves. These two compounds showed no antimicrobial activity against Staphylococcus aureus and different MRSA strains (Hou et al., 2013). It is worth to note that this isodaucane type sesquiterpenoid can also be found in the leaves of the sunflower crop (Helianthus annuus L.) and it has revealed a significant herbicidal activity. Indeed, 10-oxo-isodauc-3-en-15-al was found to inhibit coleoptile elongation and is considered as a useful allelopathic compound (Fuentes-Gandara et al., 2019). It has been found in diverse plants, such as Senecio crassiflorus (Pox.) De Candolle (Jares and Pomillo, 1989), Uvaria lucida (Moriyasu et al., 2012), Chromolaena laevigata (Misra et al., 1985) and Conza linifolia (Hussein et al., 1995). Surprisingly, this compound and its C-10 epimer which is known as sinulin A, can be found also in a marine organism, the Xisha soft coral Sinularia sp. (Qin et al., 2018). 


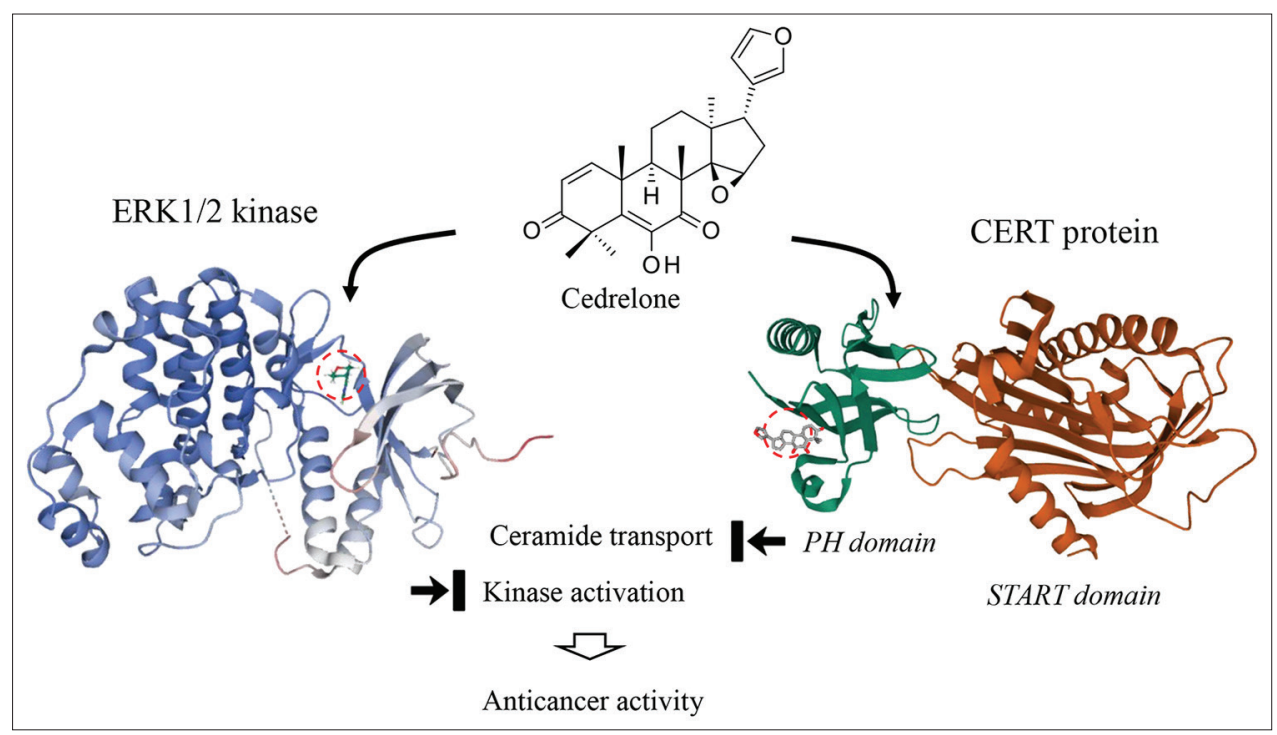

Figure 4: Two potential protein targets of the limonoid cedrelone, which can be isolated from Walsura robusta Roxb. The molecular model (left) shows a drug fragment bound to the ERK1/2 kinase, to modulate the phosphorylation and catalytic activity of the enzyme (PDB: 6G91) (Heightman et al., 2018). A molecular modeling analysis has predicted that cedrelone can bind to the same site of the protein, thereby activating the kinase (Wang et al., 2019). Molecular modeling has also predicted that cedrelone can bind to the PH domain of the multi domain ceramide transfer protein (CERT) to inhibit its transport activity (Ghoula et al., 2020). Binding of the compound to ERK1/2, CERT and other proteins likely contributes to the anticancer activity of this limonoid

\section{CONCLUSION}

Plants of the Walsura genus have been little studied thus far. For examples, the PubMed data bank comprises 30 references with the name Walsura, compared to >2000, 300 and 150 for the genera Trichilia, Aglaia and Xylocarpus, which also belong to the Meliaceae family (as of April 2021). Moreover, in the Walsura genus, the specie W. pinnata Hassk (synonyms: W. cochinchinensis (Baill.) Harms and W. yunnanensis C.Y. Wu) is more frequently studied than W. robusta Roxb. This is perhaps not surprising because the plant is not so frequently used in traditional medicine, except in very local areas. W. robusta trees should be investigated further, for the usefulness of their woods and the diversity of the secondary metabolites which can be isolated from the bark, leaves and fruits of the plant.

As presented here, W. robusta Roxb. provides a rich reservoir of limonoids, a huge family of natural products widely distributed in nature. Limonoids can be isolated from many plants, and some of them can be (semi) synthesized (Zhang and Xu, 2017; Fu and Liu, 2020). They are particularly abundant in Meliaceae (Tan and Luo, 2011). The great majority of the new natural products isolated from $W$. robusta over the past few years are limonoids, such as the walsuronoids, walrobsins, walsurins, and walsunoids. Beyond the isolation and characterization of these compounds, the bioactivity measurements have been limited mainly to a few preliminary in vitro tests, notably to evaluate their antimicrobial activity. No outstanding activity has been reported, but occasionally a few compounds revealed a modest antibacterial or anti-inflammatory effect. Two compounds emerge from this literature survey: walsuronoid B and cedrelone, because they both present noticeable anticancer properties against multiple cancer cell lines. Walsuronoid B stands as a potent anticancer agent active in a xenograft model in vivo and cedrelone also displays marked anticancer activities. They both impact mitochondrial activities, cause an increase of ROS in cells, and trigger apoptosis of cancer cells (Geng et al., 2017; Cao et al., 2019). They could be considered as prototypes for the design of novel anticancer derivatives (Becceneri et al., 2020).

Plants of the Walsura genus, and the specie W. robusta Roxb. in particular, have received little attention thus far. This robust tree, well distributed in south Asia, should be considered further in the search of natural products of medicinal interest. We can certainly recommend the investigation of extracts of the plant and its abundant fruits, for the treatment of cancers, and possibly other diseases with a cell proliferation component. The specie deserves its named "robusta", as a robust provider of bioactive limonoids.

\section{FUNDING}

This research did not receive any specific grant from funding agencies in the public, commercial, or not-for-profit sectors.

\section{DECLARATION OF COMPETING INTEREST}

The author declares no conflict of interest associated with this publication and there has been no significant financial support for this work that could have influenced its outcome.

\section{REFERENCES}

Abdullah, M. R., Haque, M., Sarwar, A. G., Ashrafuzzaman, M., \& Rahman, M. (2020). Diversity of underutilized fruits and their uses in Karnaphuli range, Rangamati, Bangladesh. International Journal of 
Forestry, Ecology and Environment, 1, 10-20.

An, F., Wang, X., Yang, M., Luo, J., \& Kong, L. (2019). Bioactive A-ring rearranged limonoids from the root barks of Walsura robusta. Acta Pharmaceutica Sinica B, 9, 545-556.

An, F. L., Sun, D. M., Li, R. J., Zhou, M. M., Yang, M. H., Yin, Y., Kong, L. Y., \& Luo, J. (2017). Walrobsins A and B, Two Anti-inflammatory Limonoids from root barks of Walsura robusta. Organic Letters, 19, 4568-4571.

Becceneri, A. B., Fuzer, A. M., Popolin, C. P., Cazal, C. M.., Domingues, V. C., Fernandes, J. B., Vieira, P. C., \& Cominetti, M. R. (2020). Acetylation of cedrelone increases its cytotoxic activity and reverts the malignant phenotype of breast cancer cells in 3D culture. Chemico-Biological Interactions, 316, 108920.

Cao, Y., Zhang, L., \& Wang, Y. (2019). Antitumor activity of Cedrelone in temozolomide-resistant human glioma cells is accompanied by mitochondrial mediated apoptosis, inhibition of angiogenesis, cell cycle disruption and modulation of ERK/MAPK signalling pathway. Journal of the Balkan Union of Oncology, 24, 1204-1209.

Cazal, C. M., Choosang, K., Severino, V. G., Soares, M. S., Sarria, A. L., Fernandes, J. B., Silva, M. F., Vieira, P. C., Pakkong, P., Almeida, G. M., Vasconcelos, M. H., Nascimento, M. S., \& Pinto, M. M. (2010). Evaluation of effect of triterpenes and limonoids on cell growth, cell cycle and apoptosis in human tumor cell line. Anti-cancer Agents in Medicinal Chemistry, 10(10), 769-776.

Chen, Y. Y., Wen, S. Y., Deng, C. M., Yin, X. F., Sun, Z. H., Jiang, M. M., \& He, Q. Y. (2019). Proteomic analysis reveals that Odoroside A triggers G2/M arrest and apoptosis in colorectal carcinoma through ROS-p53 pathway. Proteomics, 19(15), e1900092

Clark, T. P. (1994). The species of Walsura and Pseudoclausena genus novum (Meliaceae). Blumea, 38, 247-302.

Fu S, Liu B. (2020). Recent progress in the synthesis of limonoids and limonoid-like natural products. Organic Chemistry Frontiers, 7. 1903-1947.

Fuentes-Gandara, F., Torres, A., Fernández-Ponce, M. T., Casas, L., Mantell, C., Varela, R., Martínez de la Ossa-Fernández, E. J., \& Macías, F. A. (2019). Selective fractionation and isolation of allelopathic compounds from Helianthus annuus L. leaves by means of high-pressure techniques. Journal of Supercritical Fluids, 143, 32-41.

Fuzer, A. M., Filho, J. C., Becceneri, A. B., Dos Santos, D. A., da Silva, M. F., Vieira, P. C., Fernandes, J. B., Selistre-de-Araujo, H. S., Cazal, C. M., \& Cominetti, M. R. (2013). Effects of limonoid cedrelone on MDAMB-231 breast tumor cells in vitro. Anti-cancer Agents in Medicinal Chemistry, 13(10), 1645-1653.

Geng, Y. D., Zhang, C., Lei, J. L., Yu, P., Xia, Y. Z., Zhang, H., Yang, L., \& Kong, L. Y. (2017). Walsuronoid B induces mitochondrial and lysosomal dysfunction leading to apoptotic rather than autophagic cell death via ROS/p53 signaling pathways in liver cancer. Biochemical Pharmacology, 142, 71-86.

Ghosh, R. B. (1968). Studies on the morphology of somatic chromosomes in Walsura piscidia Roxb. Caryologia, 21, 111-114.

Ghoula, M., Le Marec, A., Magnan, C., Le Stunff, H., \& Taboureau, O. (2020). Identification of the interactions interference between the $\mathrm{PH}$ and START domain of CERT by limonoid and HPA inhibitors. Frontiers in Molecular Biosciences, 7, 603983.

Giongo, A. M., Vendramim, J. D., Freitas, S. D., \& Silva, M. F. (2016). Toxicity of secondary metabolites from Meliaceae against Spodoptera frugiperda (J. E. Smith) (Lepidoptera: Noctuidae). Neotropical Entomology, 45(6), 725-733.

Govindachari, T. R., Narasimhan, N. S., Suresh, G., Partho, P. D., Gopalakrishnan, G., \& Krishna Kumari, G. N. (1995). Structurerelated insect antifeedant and growth regulating activities of some limonoids. Journal of Chemical Ecology, 21(10), 1585-1600.

Govindachari, T. R., Suresh, G., Gopalakrishnan, G., Masilamani, S., \& Banumathi, B. (2000). Antifungal activity of some tetranortriterpenoids. Fitoterapia, 71, 317-320.

Haque, A. K. M. K., Khan, S. A., Uddin, S. N., \& Shetu, S. S. (2018). An annotated checklist of the angiospermic flora of Rajkandi reserve forest of Moulvibazar, Bangladesh. Bangladesh Journal of Plant Taxonomy, 25, 187-207.

Heightman, T. D., Berdini, V., Braithwaite, H., Buck, I. M., Cassidy, M., Castro, J., Courtin, A., Day, J., East, C., Fazal, L., Graham, B., GriffithsJones, C. M., Lyons, J. F., Martins, V., Muench, S., Munck, J. M., Norton, D., O'Reilly, M., Palmer, N., Pathuri, P., Reader, M., Rees, D. C., Rich, S. J., Richardson, C., Saini, H., Thompson, N. T., Wallis, N. G.,
Walton, H., Wilsher, N. E., Woolford, A. J., Cooke, M., Cousin, D. Onions, S., Shannon, J., Watts, J., \& Murray, C. W. (2018). FragmentBased Discovery of a Potent, Orally Bioavailable Inhibitor That Modulates the Phosphorylation and Catalytic Activity of ERK1/2. Journal of Medicinal Chemistry, 61, 4978-4992.

Hou, L., Tang, G. H., Zhang, Y., Hao, X. J., Zhao, Q., \& He, H-P. (2013). A new carotane sesquiterpene from Walsura robusta. Chinese Journal of Natural Medicines, 11, 84-86.

Hussein, N. S., Ahmed, A. A., Spaller, M., \& Mabry, T. J. (1995). Terpenoids from Conza linifolia. Asian Journal of Chemistry, 7, 433-435.

Jares, E. A., \& Pomillo, A. B. (1989). Isolation of Sesquiterpenes from Senecio crassiflorus Combined Dry Column and High-Performance Liquid Chromatography. Journal of Separation Science, 12, 565-568.

Ji, K. L., Zhang, P., Hu, H. B., Hua, S., Liao, S. G., \& Xu, Y. K. (2014). Limonoids from the Leaves and Twigs of Walsura yunnanensis. Journal of Natural Products, 77, 1764-1769.

Ji, K. L., Zhang, P., Li, X. N., Guo, J., Hu, H. B., Xiao, C. F., Xie, X. Q., \& Xu, Y. K. (2015). Cytotoxic limonoids from Trichilia americana leaves. Phytochemistry, 118, 61-67.

Jiang, H. U., Jia-Xun, L. I., Qiang, L. I., Tian-Feng, P., Xiao-Dong, S., Tao, L., Jian, C., Nian-Hua, J., Wei-Xing, Y., \& Wei, W. (2020). [Terpenoids from Toona sinensis]. Zhongguo Zhong Yao Za Zhi, 45, 4411-4415.

Jin, Z., Ma, J., Zhu, G., \& Zhang, H. (2019). Discovery of Novel Anticryptosporidial Activities From Natural Products by in vitro HighThroughput Phenotypic Screening. Frontiers in Microbiology, 10, 1999

Kumagai, K., Hanada, K. (2019). Structure, functions and regulation of CERT, a lipid-transfer protein for the delivery of ceramide at the ER-Golgi membrane contact sites. FEBS Letters, 593, 2366-2377.

Li, A., Yan, Q., Zhao, X., Zhong, J., Yang, H., Feng, Z., Du, Y., Wang, Y. Wang, Z., Wang, H., Zhou, Y., Liu, S., \& Nie, Y. (2016). Decreased expression of PBLD correlates with poor prognosis and functions as a tumor suppressor in human hepatocellular carcinoma. Oncotarget, 7, 524-537.

Liang, L., \& Zhang, Z. (2016). Gambogic Acid Inhibits Malignant Melanoma Cell Proliferation Through Mitochondrial p66shc/ROS-p53/BaxMediated Apoptosis. Cellular Physiology and Biochemistry, 38, 1618-1630

Luo, X.D., Wu, D. G., Cai, X. H., \& Kennelly, E. J. (2006). New antioxidant phenolic glycosides from Walsura yunnanensis. Chemistry and Biodiversity, 3, 224-230.

Misra, L. N., Jakupovic, J., Bohlmann, F., \& Schemda-Hirschmann, G. (1985). Isodaucane derivatives, norsesquiterpenes and clerodanes from chromolaena laevigata. Tetrahedron, 41, 5353-5356.

Moriyasu, M., Takeuchi, S., Ichimaru, M., Nakatani, N., Nishiyama, Y., Kato, A., Mathenge, S. G., Juma, F. D., \& ChaloMutiso, P. B. (2012). Pyrenes and pyrendiones from Uvaria lucida. Journal of Natural Medicines, 66, 453-458.

Palau, V. E., Chakraborty, K., Wann, D., Lightner, J., Hilton, K., Brannon, M., Stone, W., \& Krishnan, K. (2018). $\gamma$-Tocotrienol induces apoptosis in pancreatic cancer cells by upregulation of ceramide synthesis and modulation of sphingolipid transport. BMC Cancer, 18, 564.

Pasha, M. K., Uddi, S. B. (2019). Minor edible fruits of Bangladesh. Bangladesh Journal of Plant Taxonomy, 26, 299-313.

Qin, G. F., Tang, X. L., Sun, Y. T., Luo, X. C., Zhang, J., van Ofwegen, L., Sung, P. J., Li, P. L., \& Li, G. Q. (2018). Terpenoids from the Soft Coral Sinularia sp. Collected in Yongxing Island. Marine Drugs, 16, 127.

Sakkatat, P. (2007). Estimation of number and density, and random distribution testing of important plant species in Ban Pong Forest, Sansai District, Chiang Mai Province, Thailand using T-Square sampling. Maejo International Journal of Science and Technology, 1, 64-72.

Shen, H., Liu, L., Yang, Y., Xun, W., Wei, K., \& Zeng, G. (2017). Betulinic acid inhibits cell proliferation in human oral squamous cell carcinoma via modulating ROS-regulated p53 signaling. Oncology Research, $25,1141-1152$

Tan, O. G., \& Luo, X. D. (2011). Meliaceous limonoids: chemistry and biological activities. Chemical Reviews, 111, 7437-7522.

Tundis, R., Loizzo, M. R., \& Menichini, F. (2014). An overview on chemical aspects and potential health benefits of limonoids and their derivatives. Critical Review in Food Science and Nutrition, 54, 225-250.

Voravuthikunchai, S., Lortheeranuwat, A., Jeeju, W., Sririrak, T., Phongpaichit, S., \& Supawita, T. (2004). Effective medicinal plants against enterohaemorrhagic Escherichia coli O157:H7. Journal of 
Ethnopharmacology, 94, 49-54.

Voravuthikunchai, S. P., Kanchanapoom, T., Sawangjaroen, N., \& HutadilokTowatana, N. (2010). Antioxidant, antibacterial and antigiardial activities of Walsura robusta Roxb. Natural Products Research, 24, 813-824.

Voravuthikunchai, S. P., Kitpip, L. (2005a). Activity of medicinal plant extracts against hospital isolates of methicillin-resistant Staphylococcus aureus. Clinical Microbiology and Infection, 11, 510-551.

Voravuthikunchai, S. P., \& Kitpip, L. (2005b). Antibacterial activity of crude extracts of Thai medicinal plants against clinical isolates of methicillin-resistant Staphylococcus aureus. Journal of Science and Technology, 27, 525-534

Voravuthikunchai, S. P., \& Limsuwan, S. (2006). Medicinal plant extracts as anti-Escherichia coli 0157:H7 agents and their effects on bacterial cell aggregation. Journal of Food Protection, 69, 2336-2341.

Wang, G. C., Yu, J. H., Shen,Y., Leng, Y., Zhang, H., \& Yue, J. M. (2016). Limonoids and Triterpenoids as 11 beta-HSD1 Inhibitors from Walsura robusta. Journal of Natural Products, 79, 899-906.

Wang, N., Fan, Y., Yuan, C. M., Song, J., Yao, Y., Liu, W., Gajendran, B., Zacksenhaus, E., Li, Y., Liu, J., Hao, X. J., \& Ben-David, Y. (2019). Selective ERK1/2 agonists isolated from Melia azedarach with potent anti-leukemic activity. BMC Cancer, 19, 764.

Wu, J., Niu, Q., Yuan, J., Xu, X., \& Cao, L. (2019). Novel compound cedrelone inhibits hepatocellular carcinoma progression via PBLD and Ras/ Rap1. Experimental and Therapeutic Medicine, 18, 4209-4220.

Yin, S., Wang, X. N., Fan, C. O., Liao, S. G., and Yue, J. M. (2007). The first limonoid peroxide in the Meliaceae family: walsuronoid $A$ from Walsura robusta. Organic Letters, 9, 2353-2356.

Zhang, Y., An, F. L., Huang, S. S., Yang, L., Gu, Y. C., Luo, J., \& Kong, L. Y (2017). Diverse tritepenoids from the fruits of Walsura robusta and their reversal of multidrug resistance phenotype in human breast cancer cells. Phytochemistry, 136, 108-118.

Zhang, Y., \& Xu, H. (2017). Recent progress in the chemistry and biology of limonoids. RSC Advances, 7, 35191-35220. 